\title{
Underpowered or negative? A crucial distinction. Reply to Dollerup OL, Treebak JT, Jessen N [letter]
}

\author{
Niels J. Connell ${ }^{1} \cdot$ Riekelt H. Houtkooper ${ }^{2}$ - Patrick Schrauwen ${ }^{1}$ \\ Received: 13 March 2019 / Accepted: 13 March 2019 /Published online: 13 April 2019 \\ (C) Springer-Verlag GmbH Germany, part of Springer Nature 2019
}

Keywords Clinical trial $\cdot$ Human $\cdot \mathrm{NAD}^{+}$metabolism

To the Editor: Jessen and colleagues [1] have commented on our recent review of $\mathrm{NAD}^{+}$metabolism in Diabetologia [2]. In their letter, they comment on the discussion and citation of a clinical trial that they performed, in which dietary nicotinamide riboside was supplemented in obese men to assess the effects on whole body insulin sensitivity [3].

We concede to the argument made by Jessen and colleagues that it is important to make a clear distinction between endpoints when citing clinical trials, as this may otherwise lead to unwanted assumptions regarding the endpoint(s) that are discussed. In our review, we did not have the intention to suggest that the study by Dollerup et al [3] was underpowered for its primary endpoint, insulin sensitivity, but unfortunately omitted to add 'for these secondary endpoints', for which we do apologise. Nevertheless, the overall message and conclusion of our review does not change and we agree with Jessen and colleagues that more human studies are needed to test the efficacy of dietary supplements in rigorously designed human clinical trials.
Duality of interest The authors declare that there is no duality of interest associated with this manuscript.

Contribution statement All authors were responsible for drafting the article and revising it critically for important intellectual content. All authors approved the version to be published.

\section{References}

1. Dollerup OL, Treebak JT, Jessen N (2019) Underpowered or negative? A crucial distinction. Diabetologia. https://doi.org/10.1007/ s00125-019-4853-x

2. Connell NJ, Houtkooper RH, Schrauwen P (2019) NAD ${ }^{+}$metabolism as a target for metabolic health: have we found the silver bullet? Diabetologia. https://doi.org/10.1007/s00125-019-4831-3

3. Dollerup OL, Christensen B, Svart M et al (2018) A randomized placebo-controlled clinical trial of nicotinamide riboside in obese men: safety, insulin-sensitivity, and lipid-mobilizing effects. Am J Clin Nutr 108(2):343-353. https://doi.org/10.1093/ajcn/nqy132

Publisher's note Springer Nature remains neutral with regard to jurisdictional claims in published maps and institutional affiliations.
Patrick Schrauwen

p.schrauwen@maastrichtuniversity.nl

1 Department of Nutrition and Movement Sciences, NUTRIM School for Nutrition and Translational Research in Metabolism, Maastricht University, Universiteitssingel 50, P.O. Box 616, 6200 MD Maastricht, the Netherlands

2 Laboratory Genetic Metabolic Diseases, Amsterdam Gastroenterology and Metabolism, Amsterdam UMC, University of Amsterdam, Amsterdam, the Netherlands 